\title{
Coenzyme Q10 prevents GDP-sensitive mitochondrial uncoupling, glomerular hyperfiltration and proteinuria in kidneys from $d b / d b$ mice as a model of type 2 diabetes
}

\author{
M. Friederich Persson • S. Franzén • S.-B. Catrina • \\ G. Dallner • P. Hansell • K. Brismar • F. Palm
}

Received: 11 November 2011 / Accepted: 29 December 2011 /Published online: 5 February 2012

(C) Springer-Verlag 2012

\begin{abstract}
Aims/hypothesis Increased oxygen consumption results in kidney tissue hypoxia, which is proposed to contribute to the development of diabetic nephropathy. Oxidative stress causes increased oxygen consumption in type 1 diabetic kidneys, partly mediated by uncoupling protein-2 (UCP2)-induced mitochondrial uncoupling. The present study investigates the role of UCP-2 and oxidative stress in mitochondrial oxygen consumption and kidney function in $d b / d b$ mice as a model of type 2 diabetes.

Methods Mitochondrial oxygen consumption, glomerular filtration rate and proteinuria were investigated in $d b / d b$ mice and corresponding controls with and without coenzyme Q10 (CoQ10) treatment.

Results Untreated $d b / d b$ mice displayed mitochondrial uncoupling, manifested as glutamate-stimulated oxygen consumption $\left(2.7 \pm 0.1\right.$ vs $0.2 \pm 0.1 \mathrm{pmol} \mathrm{O}_{2} \mathrm{~s}^{-1}$ [mg protein $]^{-1}$ ), glomerular hyperfiltration ( $502 \pm 26$ vs $385 \pm 3 \mu \mathrm{l} /$ $\mathrm{min}$ ), increased proteinuria ( $21 \pm 2 \mathrm{vs} 14 \pm 1, \mu \mathrm{g} / 24 \mathrm{~h}$ ), mitochondrial fragmentation (fragmentation score $2.4 \pm 0.3$ vs $0.7 \pm 0.1)$ and size $(1.6 \pm 0.1$ vs $1 \pm 0.0 \mu \mathrm{m})$ compared with
\end{abstract}

M. F. Persson $(\bowtie) \cdot$ S. Franzén · P. Hansell • F. Palm

Department of Medical Cell Biology, Biomedical Center,

Husargatan 3, Box 571, 75123 Uppsala, Sweden

e-mail: Malou.Friederich@mcb.uu.se

S.-B. Catrina $\cdot$ G. Dallner $\cdot$ K. Brismar

Department of Molecular Medicine and Surgery,

Karolinska Institute,

Stockholm, Sweden

F. Palm

Department of Medical and Health Sciences,

Linköping University,

Linköping, Sweden untreated controls. All alterations were prevented or reduced by CoQ10 treatment. Mitochondrial uncoupling was partly inhibited by the UCP inhibitor GDP $\left(-1.1 \pm 0.1 \mathrm{pmol} \mathrm{O}_{2} \mathrm{~s}^{-1}\right.$ $[\mathrm{mg} \text { protein }]^{-1}$ ). UCP-2 protein levels were similar in untreated control and $d b / d b$ mice $(67 \pm 9$ vs $67 \pm 4$ optical density; OD) but were reduced in CoQ10 treated groups (43 \pm 2 and $38 \pm 7$ OD).

Conclusions/interpretation $d b / d b$ mice displayed oxidative stress-mediated activation of UCP-2, which resulted in mitochondrial uncoupling and increased oxygen consumption. CoQ10 prevented altered mitochondrial function and morphology, glomerular hyperfiltration and proteinuria in $d b / d b$ mice, highlighting the role of mitochondria in the pathogenesis of diabetic nephropathy and the benefits of preventing increased oxidative stress.

Keywords $d b / d b$ mice $\cdot$ Kidney $\cdot$ Mitochondria Type 2 diabetes $\cdot$ Uncoupling protein-2
Abbreviations
ANT Adenine nucleotide transporter
CoQ Coenzyme Q
$\mathrm{P}_{\mathrm{i}} \quad$ Inorganic phosphate
UCP Uncoupling protein

\section{Introduction}

The incidence of diabetic nephropathy is approximately $40 \%$ in type 2 diabetes [1] and although the prevalence of both type 1 and 2 diabetes is increasing, the population of type 2 diabetic patients is increasing more rapidly. Furthermore, the average age at onset of type 2 diabetes is constantly decreasing and is likely to result in increased incidence of diabetic nephropathy due to the possibility of 
longer duration of diabetes. The prevalence of diabetic nephropathy has increased by 33\% from 1990 to 1998 in the USA [2], and Wild et al reported that the total number of people affected worldwide will increase from 171 million in 2000 to 366 million in 2030 [3]. Approximately 45\% of all cases of end-stage renal disease, resulting in the need for dialysis or kidney transplantation, are caused by diabetic nephropathy [4]. However, the mechanism behind the development of nephropathy in type 2 diabetic patients is not yet fully understood, and this is in part related to the heterogeneity of this patient population.

Structural changes, such as accumulation of extracellular matrix, interstitial tubular fibrosis, reduced glomerular filtration area, glomerulosclerosis and glomerular basement membrane thickening are commonly associated with the development of diabetic nephropathy in patients and animal models $[5,6]$. However, increasing interest has been directed towards understanding the functional and metabolic alterations occurring well before these structural changes [7]. The metabolic alterations precede the often irreversible structural changes and are likely to be involved in the induction of structural changes in the diabetic kidney. Lately, the proximal tubule has received considerable interest as a crucial component for the development of diabetic nephropathy (for a review, see Vallon [8]), altering the view of diabetic nephropathy as being mainly a glomerular disease. As the proximal tubular cells in the kidney cortex are responsible for the majority of active tubule electrolyte transport and therefore have a high energy demand, which manifests as a high cellular content of mitochondria, diabetes-induced alterations in mitochondrial function may play an important role in the development of diabetic nephropathy.

Diabetes is closely associated with increased oxidative stress and increased oxygen consumption resulting in decreased oxygen tension in the diabetic kidney [9]. The mitochondrial electron transport chain, consisting of four complexes, is a significant source of superoxide radicals during diabetes [10]. The transport of electrons through complex I to complex IV and the subsequent reduction of molecular oxygen to water are coupled to the transport of protons across the inner mitochondrial membrane, which creates an electrochemical gradient that is used by ATPsynthase for the production of ATP from ADP and inorganic phosphate $\left(\mathrm{P}_{\mathrm{i}}\right)$. Approximately $0.2 \%$ of the total oxygen consumption is related to mitochondrial production of superoxide radicals from complexes I and III [11]. Increased mitochondrial membrane potential in diabetes has been shown to further increase the production of superoxide radicals [12]. A possible protective mechanism against diabetes-induced mitochondrial superoxide production is to decrease the membrane potential by allowing protons to cross the inner membrane independently of ATP synthesis, which is commonly referred to as mitochondrial uncoupling
$[10,13]$. Mitochondrial uncoupling is generally accomplished by uncoupling proteins (UCPs), although other mechanisms have been suggested [14]. UCP-2 is the major isoform in human [15], rat [16] and mouse kidneys [17]. Increased mitochondrial uncoupling mediated by UCP-2 has been reported in kidneys from type 1 diabetic rats [18], resulting in increased oxygen consumption, which can at least partially explain the kidney tissue hypoxia commonly observed in diabetes $[9,19]$. UCPs are directly activated by superoxide in the kidney [20]. Indeed, diabetes-induced superoxide production from mitochondria results in decreased ATP production and complex III inactivation in mitochondria isolated from renal proximal tubular cells, causing cell death. These effects are prevented by overproduction of manganese superoxide dismutase, an antioxidant enzyme localised to the mitochondria [21].

CoQ10 is a component in the mitochondrial electron transport chain, transferring electrons from complexes I and II to complex III [22]. Endogenously synthesised CoQ10 is present in all cells and membranes and has important functions for the plasma redox system and for the permeability transition pore $[23,24]$. CoQ is our only lipid-soluble endogenous antioxidant and efficiently prevents oxidation of lipids, proteins and DNA [25]. CoQ10 is antioxidative in its reduced form and is maintained reduced in the tissue by a number of mitochondrial and cytosolic enzyme systems. Interestingly, it was demonstrated in reconstituted membranes that CoQ in its oxidised form is an obligatory cofactor for UCP-2 and -3 to perform translocation of protons [26].

Deficient leptin signalling in $d b / d b$ mice results in hyperphagia, obesity and development of hyperglycaemia and dyslipidaemia at the age of about 8 weeks [27]. The $d b / d b$ mouse model of type 2 diabetes has been proposed as a suitable experimental model for studying the development of diabetic nephropathy since it in many regards parallels the human disease [28]. The present study investigated the hypothesis that $d b / d b$ mice undergo mitochondrial uncoupling mediated by UCP-2 and that this contributes to altered kidney function. The specific role of increased oxidative stress in mediating changes in mitochondrion and kidney function was investigated by applying chronic treatment with CoQ10.

\section{Methods}

Chemicals and animal procedures All chemicals were from Sigma-Aldrich (St Louis, MO, USA) and of the highest grade available if not otherwise stated. All experiments were performed in accordance with NIH guidelines for the use and care of laboratory animals and approved by the local Animal Care and Use Committee. BKS.Cg-Dock $7^{m+} /{ }^{+}$Leprdb/J $(d b / d b)$ mice and corresponding age-matched heterozygous littermates 
(control) at the age of 10-12 weeks were divided into four groups; untreated control and $d b / d b$ mice with and without chronic CoQ10. Food (standard mouse chow R70, Labfor, Lantmännen, Sweden) and water were provided ad libitum throughout the study. Treatment with CoQ10 (0.1\% in the food) was started either 2 or 7 weeks before measurements of mitochondrion and kidney function, respectively. Blood glucose levels were determined with test reagent strips (FreeStyle, Abbott, Alameda, CA, USA) from blood samples obtained from the cut tip of the tail.

Isolation of mitochondria The kidneys were rapidly removed after cervical dislocation and placed in ice-cold buffer (250 mmol/1 sucrose, $1 \mathrm{mmol} / 1$ EGTA, $10 \mathrm{mmol} / 1$ HEPES, $\mathrm{pH} 7.4,300 \mathrm{mosmol} / \mathrm{kg} \mathrm{H}_{2} \mathrm{O}$ ). Kidney cortex was isolated on ice, rinsed with buffer and homogenised in $10 \mathrm{ml}$ of buffer on ice using a Potter-Elvehjem homogeniser (800 rpm). The homogenate was transferred to pre-chilled centrifuge tubes, centrifuged at $800 \mathrm{~g}, 10 \mathrm{~min}$ at $4^{\circ} \mathrm{C}$, and the supernatant fraction was transferred to new tubes and centrifuged at $14,500 \times \mathrm{g}, 5 \mathrm{~min}, 4^{\circ} \mathrm{C}$. The pellet was gently resuspended in buffer containing $1 \mathrm{mg} / \mathrm{ml} \mathrm{BSA} \mathrm{(further}$ purified faction $\mathrm{V}$, fatty acid free) and centrifuged at $14,500 \times \mathrm{g}, 5 \mathrm{~min}, 4^{\circ} \mathrm{C}$. The final pellet was dissolved in experimental buffer $(1 \mathrm{mg} / \mathrm{ml}$ fatty acid free BSA containing $220 \mathrm{mmol} / 1 \mathrm{mannitol}, 70 \mathrm{mmol} / 1$ sucrose, $5 \mathrm{mmol} / 1 \mathrm{MgCl}_{2}$, $5 \mathrm{mmol} / 1 \mathrm{KPO}_{4}^{-}, 10 \mathrm{mmol} / 1 \mathrm{HEPES}, 0.048 \mathrm{mmol} / 1$ sodium palmitate, $\mathrm{pH} 7.4,300 \mathrm{mosmol} / \mathrm{kg} \mathrm{H}_{2} \mathrm{O}$ ). Protein concentration of the final cell suspension was measured (DC Protein Assay, Bio-Rad Laboratories, Hercules, CA, USA) and mitochondrial oxygen consumption was recorded using the Oroboros Oxygraph-2 k (Oroboros Instruments, Innsbruck, Austria).

Measurement of mitochondrial respiration and justification of the applied protocol Glutamate $(10 \mathrm{mmol} / \mathrm{l})$, ADP (400 $\mu \mathrm{mol} / \mathrm{l})$, oligomycin (12 $\mu \mathrm{g} / \mathrm{mg}$ protein) and GDP $(500 \mu \mathrm{mol} / \mathrm{l})$ were injected in succession into the respiratory chamber containing the mitochondrial suspension. Mitochondrial uncoupling can be studied during this state of low oxygen consumption. Addition of glutamate (i.e. electron-donating NADH) increases the inner mitochondrial membrane potential because of the transport of protons to the intermembrane space and any mechanism resulting in proton leak (i.e. uncoupling) across the mitochondrial inner membrane will be observed as glutamate-stimulated oxygen consumption. The subsequent addition of ADP results in a profoundly increased oxygen consumption, which is used to assess mitochondrial viability (i.e. the success of the isolation process). Addition of the ATP-synthase inhibitor oligomycin mimics the effects of ADP depletion and therefore provides a second indication of mitochondrial uncoupling. Finally, the addition of the inhibitor GDP was used to confirm any uncoupling mechanism present in mitochondria from the different groups. A sample of the mitochondrial suspension was taken from the respiration chamber at the end of each experiment and analysed for protein concentration (DC Protein Assay, Bio-Rad Laboratories). All results are expressed as oxygen consumption corrected for protein concentration.

Calculations Glutamate-stimulated oxygen consumption was calculated as oxygen consumption after addition of glutamate subtracted for the baseline oxygen consumption. The respiratory control ratio was calculated as oxygen consumption after addition of ADP divided by oxygen consumption after addition of glutamate. GDP-inhibited oxygen consumption was calculated as oxygen consumption after addition of GDP subtracted by oxygen consumption after addition of oligomycin.

Protein carbonyl content Protein carbonyl levels in kidney tissue were measured with a commercially available kit according to the manufacturer's instructions (Cayman Chemicals, Ann Arbor, MI, USA).

Western blotting Kidney cortexes were homogenised in $700 \mu$ buffer (1.0\% NP40, 0.5\% sodium deoxycholate, $0.1 \% \mathrm{SDS}, 10 \mathrm{mmol} / \mathrm{l} \mathrm{NaF}$ and $80 \mathrm{mmol} / 1$ Tris- $\mathrm{HCl}$, pH 7.5) containing enzyme inhibitors (Phosphatase Inhibitor Cocktail-2; $10 \mu \mathrm{l} / \mathrm{ml}$, and Complete Mini; 1 tablet/ $1.5 \mathrm{ml}$; Roche Diagnostics, Mannheim, Germany) using a FastPrep FP120 (Thermo Electron, Franklin, MA, USA) centrifuged at $15,000 \times \mathrm{g}, 15 \mathrm{~min}, 4^{\circ} \mathrm{C}$ and the supernatant fraction was analysed for protein concentration using the DC Protein Assay (Bio-Rad Laboratories). Equal amounts of protein were separated on a $12.5 \%$ Tris-HCl gel with Tris/ glycine/SDS buffer and the proteins were detected, after transfer to nitrocellulose membranes, using goat anti-rat UCP-2 antibody (1:1,000; Santa Cruz Biotechnology, Santa Cruz, CA, USA) and horse radish peroxidase (HRP)-conjugated secondary antibody (rabbit anti-goat, 1:10,000; Kirkegaard and Perry Laboratories, Gaithersburg, MD, USA) using an ECL camera (Kodak Image Station 2000; New Haven, CT, USA). $\beta$-Actin was detected using mouse antirat $\beta$-actin antibody $(1: 10,000)$ and secondary HRPconjugated goat anti-mouse antibody (1:60,000; Kirkegaard and Perry Laboratories). The specificity of this particular UCP-2 antibody has been verified using tissue from UCP-2 knockout mice (personal communication with M.P. Murphy, MRC Dunn, Cambridge, UK).

Metabolism cages Faeces and urine production and excretion of sodium, potassium and proteins were measured by placing animals in metabolism cages for $24 \mathrm{~h}$. Urinary sodium and potassium excretion were determined by flame 
Table 1 Body weight, blood glucose, urine and faeces production and excretion of sodium and potassium in control and $\mathrm{db} / \mathrm{db}$ mice with and without antioxidant treatment with CoQ10

\begin{tabular}{|c|c|c|c|c|c|c|}
\hline Condition & Body weight (g) & $\begin{array}{l}\text { Blood glucose } \\
(\mathrm{mmol} / \mathrm{l})\end{array}$ & $\begin{array}{l}\text { Urine output } \\
(\mathrm{ml} / 24 \mathrm{~h})\end{array}$ & $\begin{array}{l}\mathrm{Na}_{\mathrm{excr}} \\
(\mu \mathrm{mol} / 24 \mathrm{~h})\end{array}$ & $\begin{array}{l}\mathrm{K}_{\text {excr }} \\
(\mu \mathrm{mol} / 24 \mathrm{~h})\end{array}$ & $\begin{array}{l}\text { Faeces production } \\
(\mathrm{g} / 24 \mathrm{~h})\end{array}$ \\
\hline Control & $26.1 \pm 0.3$ & $6.6 \pm 0.2$ & $0.8 \pm 0.1$ & $52 \pm 10$ & $98 \pm 26$ & $0.7 \pm 0.7$ \\
\hline Control+CoQ10 & $26.5 \pm 0.5$ & $6.5 \pm 0.1$ & $1 \pm 0.1$ & $72 \pm 9$ & $143 \pm 20$ & $0.7 \pm 0.2$ \\
\hline$d b / d b$ & $43.2 \pm 1.0$ & $25.3 \pm 1.3$ & $3.8 \pm 0.8$ & $135 \pm 16$ & $215 \pm 38$ & $1.3 \pm 0.3$ \\
\hline$d b / d b+\mathrm{CoQ} 10$ & $43.7 \pm 0.7$ & $24.8 \pm 1.1$ & $3.1 \pm 0.6$ & $143 \pm 21$ & $216 \pm 34$ & $0.7 \pm 0.2$ \\
\hline \multicolumn{7}{|l|}{$2 b y 2-A N O V A$} \\
\hline Group & $*$ & $*$ & $*$ & $*$ & * & ns \\
\hline Treatment & ns & ns & ns & ns & ns & ns \\
\hline Interaction & ns & ns & ns & ns & ns & ns \\
\hline
\end{tabular}

Values are displayed as mean \pm SEM and $*$ denotes $p<0.05$

photometry (IL943, Instrumentation Laboratory, Milan, Italy) and urinary protein excretion by DC Protein Assay (Bio-Rad Laboratories). Urinary excretion rates were multiplied by urine volumes and expressed as excretion per $24 \mathrm{~h}$.
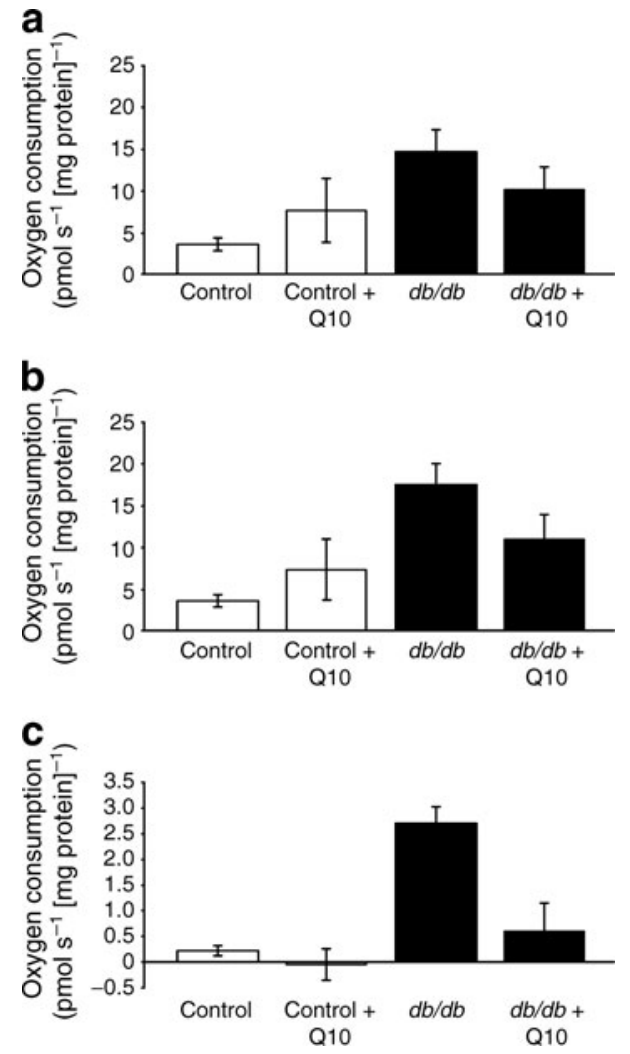

Fig. 1 Oxygen consumption at baseline (a) and after glutamate (b) and the calculated glutamate-stimulated respiration (c) in mitochondria isolated from the kidney cortex of control and $d b / d b$ mice with and without antioxidant treatment with CoQ10 (Q10). Values are displayed as mean \pm SEM. $2 \times 2$ ANOVA: (a) $p>0.05$ for type, (b) $p<0.05$ for type and interaction and (c) $p>0.05$ for type, drug and interaction. Control $n=8$; Control + Q10 $n=8 ; d b / d b n=6 ; d b / d b+\mathrm{Q} 10 n=8$
Glomerular filtration rate in conscious mice Conscious GFR was measured by the single bolus injection method of FITC-inulin clearance [29]. Briefly, 2\% FITC-inulin was dissolved in PBS and dialysed in PBS at $4{ }^{\circ} \mathrm{C}$ overnight in a
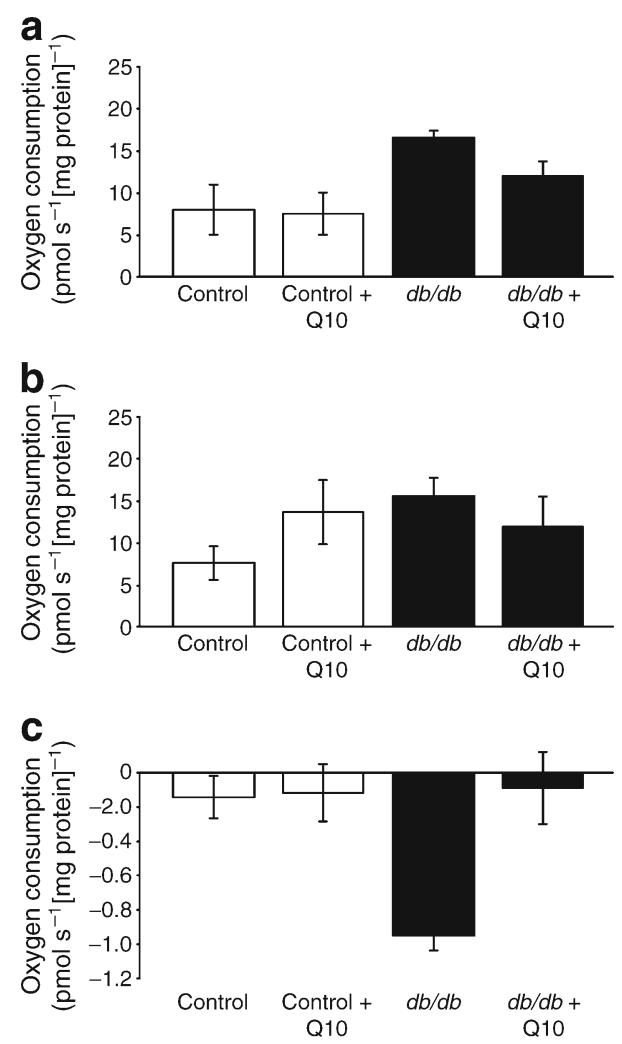

Fig. 2 Oxygen consumption after oligomycin (a) or GDP (b) and the calculated GDP-inhibited respiration (c) in mitochondria isolated from the kidney cortex of control and $d b / d b$ mice with and without antioxidant treatment with CoQ10. Values are displayed as mean \pm SEM. $2 \times 2$ ANOVA: (a) $p>0.05$ for type and interaction, (b) all NS and (c) $p>$ 0.05 for type, drug and interaction. Control $n=8$; Control $+\mathrm{Q} 10 n=8$; $d b / d b n=6 ; d b / d b+\mathrm{Q} 10 n=8$ 

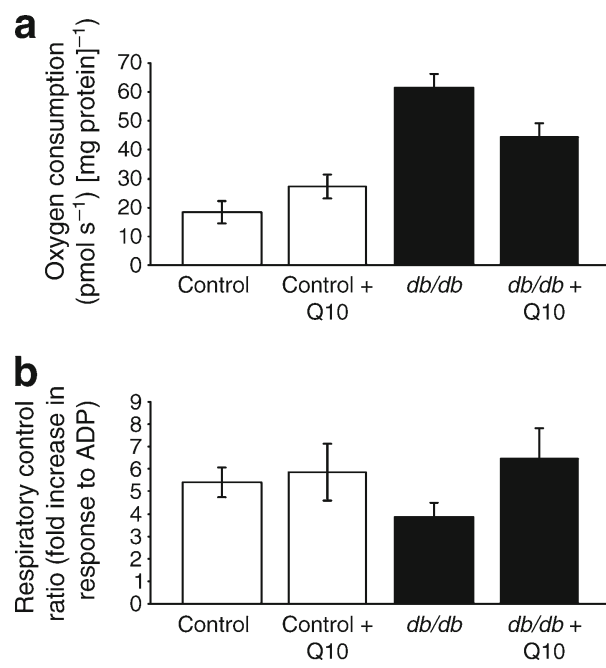

Fig. 3 Oxygen consumption after ADP (a) and the calculated respiratory control ratio (b) in mitochondria isolated from the kidney cortex of control and $d b / d b$ mice with and without antioxidant treatment with CoQ10. Values are displayed as mean \pm SEM. $2 \times 2$ ANOVA: (a) $p>$ 0.05 for type and interaction, (b) all NS. Control $n=8$; Control + Q10 $n=8 ; d b / d b n=6 ; d b / d b+\mathrm{Q} 10 n=8$

1000 Da cut-off dialysis membrane (Spectra/Por 6 Membrane, Spectrum Laboratories, Rancho Dominguez, CA, USA). FITC-inulin was filtered through $0.45 \mu \mathrm{m}$ syringe filters, $0.2 \mathrm{ml}$ injected in the tail vein, and blood samples taken at 1, 3, 7, 10, 15, 35, 55 and 75 min. Plasma samples were added to HEPES buffer (500 mmol/1, pH 7.4) and assayed for fluorescence (496 nm excitation and $520 \mathrm{~nm}$ emission, Safire II, Tecan Austria, Grödig, Austria). The exact FITC-inulin dose was calculated from syringe pre to post weight and FITC-inulin clearance was calculated using non-compartmental pharmacokinetic data analysis [30].

Electron microscopy Thin slices of renal cortex from two animals from each group were fixed in $2.5 \%$ glutaraldehyde with sodium cacodylate buffer (150 mmol/1, $\mathrm{pH} 7.4)$, post fixed in $1 \% \mathrm{OsO}_{4}$ and embedded in Agar 100 Resin (Agar Scientific, Stansted, UK). Sections were contrasted with $2 \%$ uranyl acetate and Reynolds lead citrate solution and examined in a Hitachi 7100 transmission electron microscope

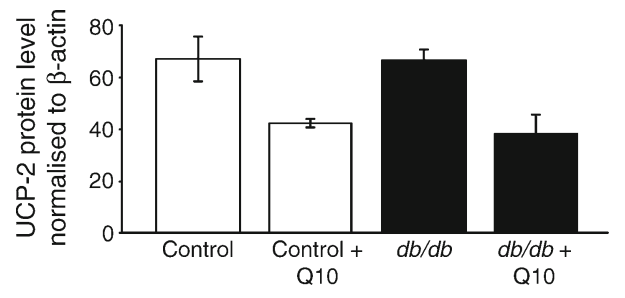

Fig. 4 UCP-2 protein levels corrected for $\beta$-actin in homogenate from the kidney cortex of control and $d b / d b$ mice with and without antioxidant treatment with CoQ10. Values are displayed as mean \pm SEM. $2 \times 2$ ANOVA: $p>0.05$ for drug. Control $n=5$; Control $+\mathrm{Q} 10 n=6 ; d b / d b$ $n=6 ; d b / d b+\mathrm{Q} 10 n=6$

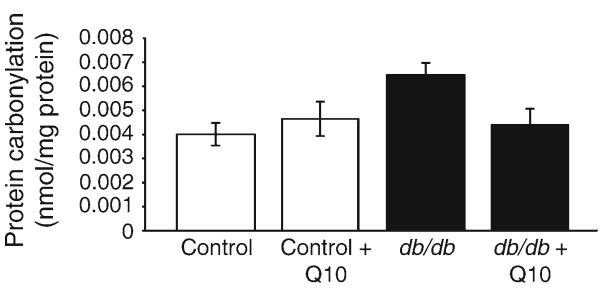

Fig. 5 Protein carbonyl content in kidney cortex homogenate of controls and $d b / d b$ mice with and without antioxidant treatment with CoQ10. Values are displayed as mean \pm SEM. $2 \times 2$ ANOVA: $p>0.05$ for type and interaction. Control $n=8$; Control $+\mathrm{Q} 10 n=7 ; d b / d b n=7$; $d b / d b+\mathrm{Q} 10 n=8$

(Tokyo, Japan). Electron micrographs were taken with a Gatan multiscan camera model 791 using Gatan digital software version 3.6.4 (Gatan, Pleasanton, CA, USA). Representative mitochondria were selected by superimposing an $8 \times 5$ grid onto the micrographs and selecting those that were located in an intersection of the grids. Mitochondrion size was determined by measuring the longest distance of each mitochondrion. Fragmentation was scored from 0 to $4(0$ representing no fragmentation, 4 representing full fragmentation). Percent intracellular content of mitochondria was also calculated. All mitochondrial micrograph analyses were performed by the same blinded investigator.

Statistical analysis Statistical comparisons were performed with $2 \times 2$ ANOVA; $p<0.05$ was considered significant and all values are presented as mean values \pm SEM.

\section{Results}

$d b / d b$ mice had increased body weights, blood glucose levels, urinary flow, and urinary excretion of sodium and potassium compared with controls (Table 1). Mitochondrial oxygen consumption at baseline (Fig. 1a), after addition of glutamate (Fig. 1b) and the calculated glutamate-stimulated oxygen consumption (Fig. 1c) were higher in untreated $d b$ / $d b$ mice compared with corresponding controls.

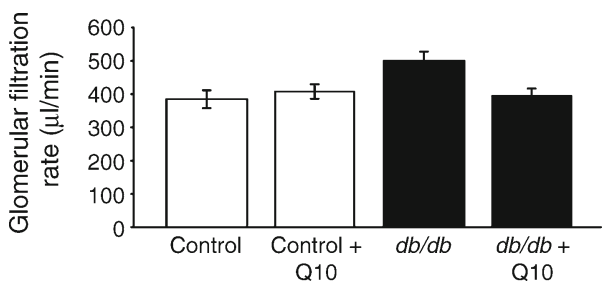

Fig. 6 GFR in conscious controls and $d b / d b$ mice with and without antioxidant treatment with CoQ10. Values are displayed as mean \pm SEM. $2 \times 2$ ANOVA: $p>0.05$ for type and interaction. Control $n=11$; Control + Q10 $n=10 ; d b / d b n=10 ; d b / d b+\mathrm{Q} 10 n=10$ 


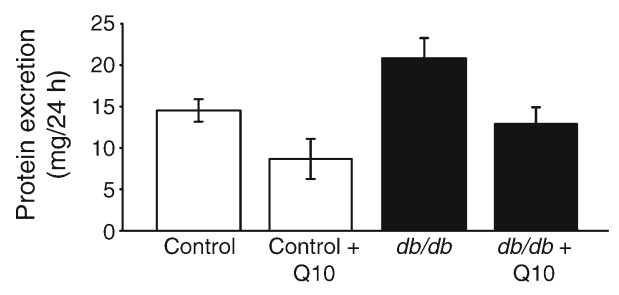

Fig. 7 Urinary protein excretion per $24 \mathrm{~h}$ in controls and $d b / d b$ mice with and without antioxidant treatment with CoQ10. Values are displayed as mean \pm SEM. $2 \times 2$ ANOVA: $p>0.05$ for type, drug and interaction. Control $n=9$; Control $+\mathrm{Q} 10 n=10 ; d b / d b$ $n=10 ; d b / d b+\mathrm{Q} 10 n=10$

Oxygen consumption after addition of oligomycin was higher in $d b / d b$ mice (Fig. 2a). However, the oxygen consumption after administration of GDP was similar in all groups (Fig. 2b). This resulted in a greater proportion of oxygen consumption inhibited by GDP in mitochondria from untreated $d b / d b$ mice (Fig. 2c), compared with untreated control mice. Treatment with CoQ10 for 2 weeks prevented diabetes-induced differences in mitochondrial oxygen consumption in response to both glutamate and GDP (Figs 1 and 2). Addition of ADP caused a profound increase in oxygen consumption in all groups, with the mitochondria from untreated $d b / d b$ mice displaying the highest oxygen consumption (Fig. 3a). However, the calculated respiratory control ratios were similar in all investigated groups (Fig. 3b). The UCP-2 protein level corrected for $\beta$-actin was similar in both untreated groups and treatment with CoQ10 resulted in decreased UCP-2 levels in both groups (Fig. 4). Protein carbonyl levels were increased in untreated $d b / d b$ mice and reduced by CoQ10. No differences were detected in controls (Fig. 5).

CoQ10 prevented glomerular hyperfiltration and proteinuria in $d b / d b$ mice but had no effect in controls. CoQ10 did not affect glomerular hyperfiltration but reduced proteinuria in controls (Figs 6 and 7). Untreated $d b / d b$ mice displayed increased mitochondrial fragmentation compared with
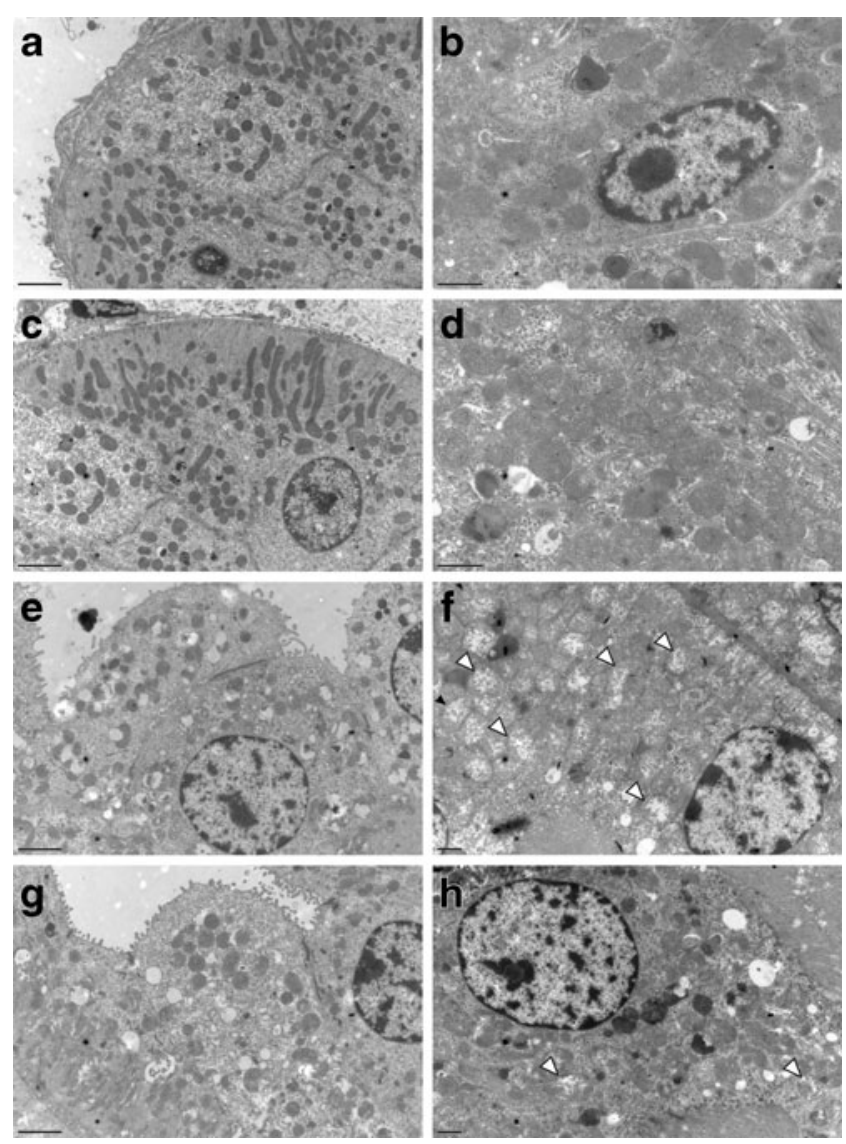

Fig. 8 Representative electron micrographs of kidney cortex from untreated controls $(\mathbf{a}, \mathbf{b}), \mathrm{CoQ} 10$-treated controls $(\mathbf{c}, \mathbf{d})$, untreated $d b /$ $d b$ mice $(\mathbf{e , f})$ and CoQ10-treated $d b / d b$ mice $(\mathbf{g}, \mathbf{h})$. Arrowheads indicate fragmented mitochondria

untreated control animals, which was reduced by CoQ10 (Table 2 and Fig. 8). Cellular mitochondrion content, fragmentation and size were increased in both $d b / d b$ groups compared with untreated controls but only mitochondrion size and fragmentation were reduced by CoQ10 (Table 2).

Table 2 Mitochondrial size and fragmentation score and cellular content of mitochondria analysed in control and $d b / d b$ mice with and without antioxidant treatment with CoQ10

\begin{tabular}{|c|c|c|c|c|c|c|c|}
\hline Condition & $\begin{array}{l}\text { Mitochondrion } \\
\text { size }(\mu \mathrm{m})\end{array}$ & $\begin{array}{l}n \text { of analysed } \\
\text { images }\end{array}$ & $\begin{array}{l}n \text { of analysed } \\
\text { mitochondria }\end{array}$ & $\begin{array}{l}\text { Fragmentation } \\
\text { score }(1-4)\end{array}$ & $\begin{array}{l}n \text { of analysed } \\
\text { images }\end{array}$ & $\begin{array}{l}\text { Cell mitochondrion } \\
\text { content }(\%)\end{array}$ & $\begin{array}{l}n \text { of analysed } \\
\text { images }\end{array}$ \\
\hline Control & $1 \pm 0.0$ & 49 & 1003 & $0.7 \pm 0.1$ & 53 & $41.0 \pm 3.4$ & 10 \\
\hline Control+CoQ10 & $1.2 \pm 0.0$ & 31 & 619 & $0.9 \pm 0.2$ & 31 & $37.2 \pm 4.1$ & 7 \\
\hline$d b / d b$ & $1.6 \pm 0.1$ & 26 & 509 & $2.4 \pm 0.3$ & 26 & $47.6 \pm 2.5$ & 9 \\
\hline$d b / d b+$ CoQ10 & $0.96 \pm 0.0$ & 32 & 521 & $1.4 \pm 0.2$ & 34 & $45 \pm 3.6$ & 10 \\
\hline \multicolumn{8}{|l|}{ 2by2-ANOVA } \\
\hline Group & $*$ & & & $*$ & & $*$ & \\
\hline Treatment & $*$ & & & $*$ & & ns & \\
\hline Interaction & $*$ & & & ns & & ns & \\
\hline
\end{tabular}

Values are displayed as mean \pm SEM and $*$ denotes $p<0.05$ 


\section{Discussion}

The main finding of the present study is that mitochondria from the kidney cortex of $d b / d b$ mice display glutamatestimulated oxygen consumption in the absence of ADP. Taken together with the finding that the glutamate-stimulated oxygen consumption is inhibited by GDP, this demonstrates the presence of mitochondrial uncoupling, at least in part mediated by UCP-2. However, glutamate increased oxygen consumption by approximately $2.5 \mathrm{pmol} \mathrm{s}^{-1}$ (mg protein) $)^{-1}$, whereas GDP only inhibited oxygen consumption by about $1 \mathrm{pmol} \mathrm{s}^{-1}$ (mg protein $)^{-1}$. This suggests that at least one additional mechanism is involved in mitochondrial uncoupling in $\mathrm{db} / \mathrm{db}$ mice. Echtay et al demonstrated that adenine nucleotide transporter (ANT) plays a role in the fatty acid-induced uncoupling of kidney mitochondria [14]. Indeed, several studies have demonstrated that $d b / d b$ mice are dyslipidaemic with increased plasma levels of cholesterol and triacylglycerol [31, 32]. However, the role of ANT-mediated mitochondrial uncoupling was beyond the scope of the present study.

Mitochondrial uncoupling in hyperglycaemic $d b / d b$ mice was prevented by CoQ10 treatment for 2 weeks, indicating a pivotal role of oxidative stress in regulating mitochondrial function. Interestingly, UCP-2 protein levels were similar in untreated controls and untreated $d b / d b$ mice, suggesting activation of existing UCP-2 rather than dependence on new protein synthesis. Activation of kidney UCP-2 by superoxide has previously been reported [20,33] although it is debated [20, 34]. However, Krauss et al used UCP-2 deficient mice to demonstrate that mitochondria isolated from both kidney and spleen completely lacked superoxide-inducible oxygen consumption [35]. In the same study it was also shown that wildtype mitochondria incubated with the superoxide dismutase mimetic Mn(III) tetrakis (4-benzoicacid) porphyrin (MnTBAP) had reduced proton leak. Notably, no such effect was observed in mitochondria from UCP-2 deficient mice. It is our understanding that this study convincingly demonstrated that superoxide activates mitochondrial uncoupling via UCP-2 in the kidney. It is important to note that CoQ10 reduced UCP-2 protein levels in both controls and $d b / d b$ mice but only reduced oxidative stress in $d b / d b$ mice. Therefore, direct regulation of UCP-2 protein levels by CoQ10 cannot be excluded. Importantly, mitochondrial uncoupling correlated with increased oxidative stress, evident as increased glutamate-stimulated oxygen consumption in mitochondria from untreated $d b / d b$ mice, and was normalised by CoQ10 treatment. These results imply that oxidative stress participates in the regulation of UCP-2 activity, although not affecting protein levels to the same extent in these mice as in our previous reports from streptozotocin-induced rat models of diabetes [16, 18]. Ucp2 mRNA levels were not included in the present study since UCP-2 protein production is under translational control by glutamine [36].
Altered kidney mitochondrion morphology has previously been reported during diabetes [37] and can cause increased mitochondrial production of superoxide radicals under hyperglycaemia [12]. Indeed, increased mitochondrion size and fragmentation were observed in untreated $d b / d b$ mice, and are likely to contribute to increased superoxide production in $d b / d b$ mice. Furthermore, superoxide radicals cause UCP-2 activation via lipid peroxidation products [14]. Indeed, protein carbonyl content was increased in $d b / d b$ mice and reduced after CoQ10 treatment, correlating with reduced mitochondrial fragmentation, size and uncoupling. However, increased production of superoxide in diabetes may also originate from other sources, including NADPH oxidase [38]. Since it is the total oxidative stress status that may alter kidney function and result in the development of diabetic nephropathy, we opted to use markers of end-target damage such as protein and lipid modifications. Importantly, treatment with CoQ10 reduced both mitochondrial fragmentation and size, indicating that mitochondriontargeted antioxidant treatment may protect against altered morphology and function in diabetes.

A second set of in vivo experiments was performed in order to investigate whether CoQ10 has any beneficial effects on kidney function in diabetes. Clinical studies using antioxidant interventions in diabetic nephropathy have, to date, shown disappointing results [39, 40], possibly due to starting treatment when established damage already exists. However, in animal studies, where antioxidant intervention is started prior to or at the onset of diabetes, kidney damage can be prevented $[9,41]$. Therefore, kidney function was evaluated after 7 weeks of chronic CoQ10 treatment starting prior to the onset of hyperglycaemia. $d b / d b$ mice had increased urine flow together with increased excretion of sodium and potassium, as a result of the inability to

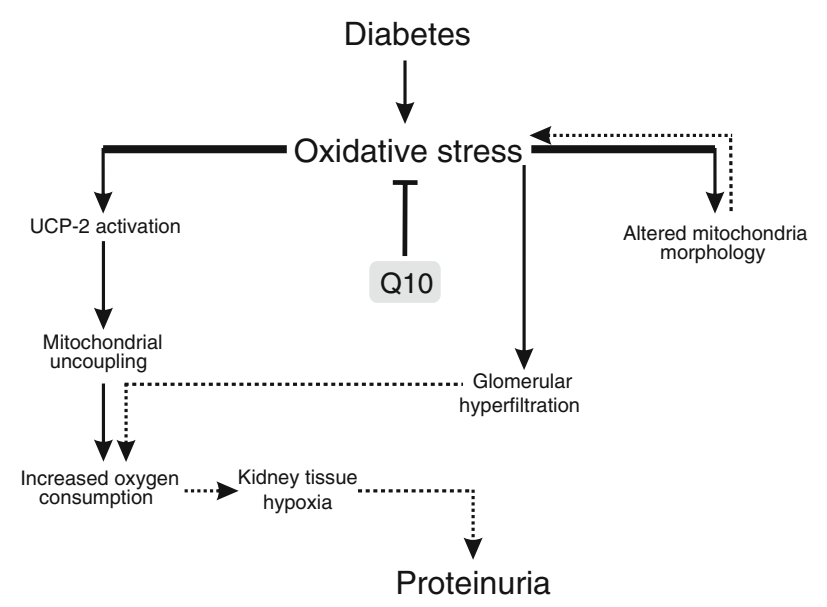

Fig. 9 The proposed mechanism for the development of diabetic nephropathy in $d b / d b$ mice. Solid arrows represent steps supported by data from the present study whereas dashed arrows represent steps supported by the literature 
correctly regulate plasma glucose levels resulting in increased food and water intake. Untreated $d b / d b$ animals developed proteinuria, a clinical hallmark of established kidney damage and the development of diabetic nephropathy [42]. These animals also displayed increased glomerular hyperfiltration, an early indicator of altered kidney function [43] and a known predictor of developing diabetic nephropathy [44]. Importantly, both the proteinuria and the glomerular hyperfiltration were prevented by antioxidative treatment. It is evident from the present study that administration of CoQ10 to $d b / d b$ mice is beneficial for preventing diabetes-induced alterations in both mitochondrial and kidney functions. The intrarenal antioxidant defence system is reduced in several animal models of both types of diabetes, including the $d b / d b$ mice [45], streptozotocin-induced diabetic rats [46] and C57BL/6-Akita mice [47]. It must be taken into consideration that the level of CoQ10 in $d b / d b$ mice is approximately $20 \%$ higher than in controls (G Dallner, unpublished observation) but the level of oxidative stress in $d b / d b$ mice clearly exceeds the antioxidant defences, thus making CoQ10 supplementation favourable.

In conclusion, mitochondria isolated from the kidney cortex of type- 2 diabetic $d b / d b$ mice display mitochondrial uncoupling. The mechanism for upregulation of mitochondrial uncoupling in these mice involves activation of the UCP-2 protein by oxidative stress rather than increased UCP-2 protein levels. Increased mitochondrial uncoupling may be a mechanism to limit oxidative damage to the mitochondria at the expense of increased oxygen consumption. Increased oxygen consumption may contribute to kidney tissue hypoxia, which is a common pathway in end-stage renal disease [48]. It should be noted that diabetic patients are more susceptible to additional ischaemic insult, such as contrast-induced acute kidney injury [49] or non-steroidal anti-inflammatory drug (NSAID)-induced ischaemic injury [50]. Importantly, CoQ10 reduces oxidative stress and UCP-2 mediated uncoupling, which results in normalised oxygen consumption in this type 2 diabetic model. In addition, treatment with CoQ10 prevents altered mitochondrion morphology, development of proteinuria and glomerular hyperfiltration (Fig. 9).

Funding This study was supported by the Swedish Research Council, The Swedish Diabetes Foundation, Family Erling-Persson Foundation, The European Commission project FUNCFOOD (FP7-KBBE-2009245030), and NIH/NIDDK K99/R00 grant (DK-07785). Parts of this study were presented in abstract form at the International Q10 Association Conference, Brussels, Belgium 2010.

Duality of interest The authors declare that there is no duality of interest associated with this manuscript.

Contribution statement MFP, SBC, GD, KB, PH and FP were responsible for the conception and design of the study. MFP, SF and
FP were responsible for analysis and interpretation of data, and for drafting the article. MFP, SF, SBC, GD, PH, KB and FP were responsible for revising the article critically for intellectual content. All authors gave final approval of the version to be published.

\section{References}

1. Thomas MC, Weekes AJ, Broadley OJ, Cooper ME, Mathew TH (2006) The burden of chronic kidney disease in Australian patients with type 2 diabetes (the NEFRON study). Med J Aust 185:140 144

2. Mokdad AH, Ford ES, Bowman BA et al (2000) Diabetes trends in the U.S.: 1990-1998. Diabetes Care 23:1278-1283

3. Wild S, Roglic G, Green A, Sicree R, King H (2004) Global prevalence of diabetes: estimates for the year 2000 and projections for 2030. Diabetes Care 27:1047-1053

4. Harvey JN (2003) Trends in the prevalence of diabetic nephropathy in type 1 and type 2 diabetes. Curr Opin Nephrol Hypertens 12:317322

5. Steffes MW, Bilous RW, Sutherland DE, Mauer SM (1992) Cell and matrix components of the glomerular mesangium in type I diabetes. Diabetes 41:679-684

6. Mauer SM, Steffes MW, Ellis EN, Sutherland DE, Brown DM, Goetz FC (1984) Structural-functional relationships in diabetic nephropathy. J Clin Invest 74:1143-1155

7. Mauer M, Drummond K (2002) The early natural history of nephropathy in type 1 diabetes: I. Study design and baseline characteristics of the study participants. Diabetes 51:1572-1579

8. Vallon V (2011) The proximal tubule in the pathophysiology of the diabetic kidney. Am J Physiol Regul Integr Comp Physiol 300: R1009-R1022

9. Palm F, Cederberg J, Hansell P, Liss P, Carlsson PO (2003) Reactive oxygen species cause diabetes-induced decrease in renal oxygen tension. Diabetologia 46:1153-1160

10. Nishikawa T, Edelstein D, Du XL et al (2000) Normalizing mitochondrial superoxide production blocks three pathways of hyperglycaemic damage. Nature 404:787-790

11. St-Pierre J, Buckingham JA, Roebuck SJ, Brand MD (2002) Topology of superoxide production from different sites in the mitochondrial electron transport chain. J Biol Chem 277:44784-44790

12. Yu T, Robotham JL, Yoon Y (2006) Increased production of reactive oxygen species in hyperglycemic conditions requires dynamic change of mitochondrial morphology. Proc Natl Acad Sci USA 103:2653-2658

13. Miwa S, Brand MD (2003) Mitochondrial matrix reactive oxygen species production is very sensitive to mild uncoupling. Biochem Soc Trans 31:1300-1301

14. Echtay KS, Esteves TC, Pakay JL et al (2003) A signalling role for 4-hydroxy-2-nonenal in regulation of mitochondrial uncoupling. EMBO J 22:4103-4110

15. Fleury C, Neverova M, Collins S et al (1997) Uncoupling protein2: a novel gene linked to obesity and hyperinsulinemia. Nat Genet 15:269-272

16. Friederich M, Nordquist L, Olerud J, Johansson M, Hansell P, Palm F (2009) Identification and distribution of uncoupling protein isoforms in the normal and diabetic kidney. Adv Exp Med Biol 645:205-212

17. Alan L, Smolkova K, Kronusova E, Santorova J, Jezek P (2009) Absolute levels of transcripts for mitochondrial uncoupling proteins UCP2, UCP3, UCP4, and UCP5 show different patterns in rat and mice tissues. J Bioenerg Biomembr 41:71-78

18. Friederich M, Fasching A, Hansell P, Nordquist L, Palm F (2008) Diabetes-induced up-regulation of uncoupling protein-2 results in 
increased mitochondrial uncoupling in kidney proximal tubular cells. Biochim Biophys Acta 1777:935-940

19. Rosenberger C, Khamaisi M, Abassi Z et al (2008) Adaptation to hypoxia in the diabetic rat kidney. Kidney Int 73:34-42

20. Echtay KS, Murphy MP, Smith RA, Talbot DA, Brand MD (2002) Superoxide activates mitochondrial uncoupling protein 2 from the matrix side. Studies using targeted antioxidants. J Biol Chem 277:47129-47135

21. Munusamy S, MacMillan-Crow LA (2009) Mitochondrial superoxide plays a crucial role in the development of mitochondrial dysfunction during high glucose exposure in rat renal proximal tubular cells. Free Radic Biol Med 46:1149-1157

22. Crane FL, Hatefi Y, Lester RL, Widmer C (1957) Isolation of a quinone from beef heart mitochondria. Biochim Biophys Acta 25:220-221

23. Sun IL, Sun EE, Crane FL, Morre DJ, Lindgren A, Low H (1992) Requirement for coenzyme $\mathrm{Q}$ in plasma membrane electron transport. Proc Natl Acad Sci USA 89:11126-11130

24. Fontaine E, Bernardi P (1999) Progress on the mitochondrial permeability transition pore: regulation by complex I and ubiquinone analogs. J Bioenerg Biomembr 31:335-345

25. Frei B, Kim MC, Ames BN (1990) Ubiquinol-10 is an effective lipid-soluble antioxidant at physiological concentrations. Proc Natl Acad Sci USA 87:4879-4883

26. Echtay KS, Winkler E, Frischmuth K, Klingenberg M (2001) Uncoupling proteins 2 and 3 are highly active $\mathrm{H}(+)$ transporters and highly nucleotide sensitive when activated by coenzyme Q (ubiquinone). Proc Natl Acad Sci USA 98:1416-1421

27. Lee SM, Bressler R (1981) Prevention of diabetic nephropathy by diet control in the $\mathrm{db} / \mathrm{db}$ mouse. Diabetes 30:106-111

28. Cohen MP, Clements RS, Hud E, Cohen JA, Ziyadeh FN (1996) Evolution of renal function abnormalities in the $\mathrm{db} / \mathrm{db}$ mouse that parallels the development of human diabetic nephropathy. Exp Nephrol 4:166-171

29. Stridh S, Sallstrom J, Friden M, Hansell P, Nordquist L, Palm F (2009) C-peptide normalizes glomerular filtration rate in hyperfiltrating conscious diabetic rats. Adv Exp Med Biol 645:219-225

30. Gabrielsson J, Weiner P (2006) Non-compartmental analysis. In: Pharmacokinetic and pharmacodynamic data analysis: concepts and applications. Swedish Pharmaceutical Press, Stockholm

31. Kobayashi K, Forte TM, Taniguchi S, Ishida BY, Oka K, Chan L (2000) The $\mathrm{db} / \mathrm{db}$ mouse, a model for diabetic dyslipidemia: molecular characterization and effects of Western diet feeding. Metabolism 49:22-31

32. How OJ, Aasum E, Severson DL, Chan WY, Essop MF, Larsen TS (2006) Increased myocardial oxygen consumption reduces cardiac efficiency in diabetic mice. Diabetes 55:466-473

33. Echtay KS, Roussel D, St-Pierre J et al (2002) Superoxide activates mitochondrial uncoupling proteins. Nature 415:96-99

34. Couplan E, del Mar Gonzalez-Barroso M, Alves-Guerra MC, Ricquier D, Goubern M, Bouillaud F (2002) No evidence for a basal, retinoic, or superoxide-induced uncoupling activity of the uncoupling protein 2 present in spleen or lung mitochondria. J Biol Chem 277:26268-26275
35. Krauss S, Zhang CY, Scorrano L et al (2003) Superoxide-mediated activation of uncoupling protein 2 causes pancreatic beta cell dysfunction. J Clin Invest 112:1831-1842

36. Hurtaud C, Gelly C, Chen Z, Levi-Meyrueis C, Bouillaud F (2007) Glutamine stimulates translation of uncoupling protein $2 \mathrm{mRNA}$. Cell Mol Life Sci 64:1853-1860

37. Kaneda K, Iwao J, Sakata N, Takebayashi S (1992) Correlation between mitochondrial enlargement in renal proximal tubules and microalbuminuria in rats with early streptozotocin-induced diabetes. Acta Pathol Jpn 42:855-860

38. Asaba K, Tojo A, Onozato ML et al (2005) Effects of NADPH oxidase inhibitor in diabetic nephropathy. Kidney Int 67:1890 1898

39. Lonn E, Yusuf S, Hoogwerf B et al (2002) Effects of vitamin E on cardiovascular and microvascular outcomes in high-risk patients with diabetes: results of the HOPE study and MICRO-HOPE substudy. Diabetes Care 25:1919-1927

40. Alkhalaf A, Klooster A, van Oeveren W et al (2010) A double-blind, randomized, placebo-controlled clinical trial on benfotiamine treatment in patients with diabetic nephropathy. Diabetes Care 33:15981601

41. Haidara MA, Mikhailidis DP, Rateb MA et al (2009) Evaluation of the effect of oxidative stress and vitamin E supplementation on renal function in rats with streptozotocin-induced type 1 diabetes. $\mathrm{J}$ Diabetes Complications 23:130-136

42. Mogensen CE (1984) Microalbuminuria predicts clinical proteinuria and early mortality in maturity-onset diabetes. N Engl J Med 310:356-360

43. O'Donnell MP, Kasiske BL, Keane WF (1988) Glomerular hemodynamic and structural alterations in experimental diabetes mellitus. FASEB J 2:2339-2347

44. Rudberg S, Persson B, Dahlquist G (1992) Increased glomerular filtration rate as a predictor of diabetic nephropathy - an 8-year prospective study. Kidney Int 41:822-828

45. Ghosh S, Khazaei M, Moien-Afshari F et al (2009) Moderate exercise attenuates caspase- 3 activity, oxidative stress, and inhibits progression of diabetic renal disease in $\mathrm{db} / \mathrm{db}$ mice. Am J Physiol Renal Physiol 296:F700-F708

46. Peixoto EB, Pessoa BS, Biswas SK, Lopes de Faria JB (2009) Antioxidant SOD mimetic prevents NADPH oxidaseinduced oxidative stress and renal damage in the early stage of experimental diabetes and hypertension. Am J Nephrol 29:309-318

47. Fujita H, Fujishima H, Chida $\mathrm{S}$ et al (2009) Reduction of renal superoxide dismutase in progressive diabetic nephropathy. J Am Soc Nephrol 20:1303-1313

48. Nangaku M (2006) Chronic hypoxia and tubulointerstitial injury: a final common pathway to end-stage renal failure. J Am Soc Nephrol 17:17-25

49. McCullough PA, Adam A, Becker CR et al (2006) Risk prediction of contrast-induced nephropathy. Am J Cardiol 98:27K-36K

50. House AA, Silva Oliveira S, Ronco C (2007) Anti-inflammatory drugs and the kidney. Int J Artif Organs 30:1042-1046 